\title{
Acoustical Abilities of Woven Bamboo to Absorbing and Transmitting of the Sound
}

\author{
Suyatno \\ Departemen of Physics \\ Institut Teknologi Sepuluh nopember \\ Surabaya, Indonesia \\ kangyatno@physics.its.ac.id
}

\author{
Dita M.A.N \\ Departemen of Physics \\ Institut Teknologi Sepuluh nopember \\ Surabaya, Indonesia \\ ditandyaningrum@gmail.com
}

\author{
Indrawati S \\ Department of Physics \\ Institut Teknologi Sepuluh nopember \\ Surabaya, Indonesia \\ susilo.indra.its@gmail.com
}

\begin{abstract}
Bamboo is mostly used in the architectural and room interior scope as additional material for room aesthetics. Handicrafts that are often used for this scope are woven bamboo in the form of sheets or board. This study aims to determine the acoustic abilities of bamboo woven panels based on the absorption coefficient and transmission loss values. The specimens of this study are thick woven bamboo, thin woven bamboo, and a combination of the two materials mentioned before. The process of measuring the absorption coefficient refers to the ASTM C-432 method and for measuring transmission loss refers to the ASTM E-90 and ASTM 413 methods to calculate the sound transmission class. Based on the results obtained in this study, it is known that woven bamboo can absorb sound at frequencies of $1250 \mathrm{~Hz}$ to $5000 \mathrm{~Hz}$. the largest absorption coefficient is 0.45 at $2500 \mathrm{~Hz}$ frequency which is owned by thin woven bamboo stacked with thick woven bamboo. Woven bamboo can transmit sound which is quite high that is thin bamboo woven material which has the largest noise reduction value of $34 \mathrm{~dB}$ at a $200 \mathrm{~Hz}$ frequency and has the largest STC value that is STC 19
\end{abstract}

Keywords: bamboo woven, absorption coefficient, transmission loss, STC

\section{INTRODUCTION}

Increasing population growth also has an impact on housing needs. While the availability of natural materials, especially thinning wood makes the making or discovery of alternative materials as a substitute for wood. If viewed in terms of acoustic properties, the use of the material is broadly outlined as an absorber, reflector, insulation, resonator up to the diffuser. One alternative non-wood material that can be used as an acoustic panel is bamboo. Bamboo is a natural product that can be obtained easily, cheaply, and has a relatively short planting period. Fig. 1 shows some uses of bamboo material in the world of construction and architecture.
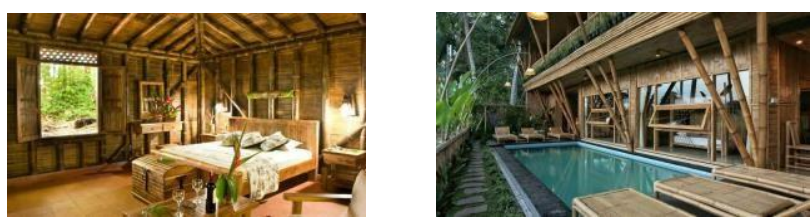

Fig. 1. Application bamboo material for building (source google)
As an alternative material, the use of bamboo in buildings has been used for a long time, starting from house building, to ornament or home or room interior design. In the field of architecture, bamboo is widely used as a partition between rooms or as an addition to the interior aesthetics of space. Karlinasari has examined the sound transmission loss (STL) and the absorption coefficient $(\alpha)$ of sound from bamboo boards made base on densities and particle sizes [6]. From the research, it was found that one of the results was that the acoustic properties of these boards had good characteristics in the high-frequency range. In the field of structure, Widjaja states that bamboo has a tensile strength that almost matches the tensile strength of reinforced iron [7]. While Pinto also stated that the maximum load value of bamboo reinforced concrete beam with 2D12 reinforcement reached up to $56.61 \%$ of the maximum load value of steel-reinforced concrete beams [8]. Even the use of bamboo has begun to be applied as fillers on concrete walls so that bamboo material is a strong ingredient.

The sound absorption coefficient is a value that shows the ability of the material to absorb sound. The factors that influence sound absorption are material density, elastic modulus, moisture content, temperature, intensity and sound frequency, and conditions on the surface of the material. The sound-absorbing coefficient or absorption coefficient $(\alpha)$ is defined as the ratio between sound energy absorbed by a material and the sound energy coming on the surface of the material which can be mathematically written in equation (1):

$$
\alpha=\frac{\text { absorption energy }}{\text { incident energy }}
$$

The value of $\alpha$ is 0 to 1 . Zero means the material is reflective, while 1 is very absorptive. The absorption coefficient value can be obtained using a reverberation time measurement $\left(\mathrm{T}_{60}\right)[1]$.

Reverberation Time $\left(\mathrm{T}_{60}\right)$ is defined as the time required by the sound pressure in the room to decay or decrease by 60 $\mathrm{dB}$ since the sound source is stopped (stops emitting sound). Mathematically, the relationship between $\mathrm{T}_{60}$ and the absorption coefficient like in equation (2)

$$
T_{60}=\frac{0.161 V}{\Sigma \alpha S}
$$


of woven bamboo when the use for an interior material, while measurement of insulation was intended to determine the ability to isolate the sound passing through it as partitions. The measurement of the sound absorption coefficient is carried out in a reverberation room based on ISO 354 and for sound insulation capabilities based on ISO 354. The absorption coefficient and STL measurements at the Acoustic laboratory Departement of Physics ITS Surabaya and analyze by using the Yoshimasa Electronic (YMEC) real-time analyzer software.

To obtain optimal results related to applications in the field, measurements were made on several variations of that test, $\alpha_{1}$ is the coefficient of absorption of material covered by test material, $\mathrm{S}$ is the area of material that test $\left(\mathrm{m}^{2}\right), \mathrm{V}$ is the volume of the test chamber $\left(\mathrm{m}^{3}\right), \mathrm{T}_{1}$ is the reverberation time when there is no material test $(\mathrm{s})$ and $\mathrm{T}_{2}$ is a reverberation time when there is a material that test (s) [2].

Another performance of acoustic materials is determined by the ability to isolate the sound that called is Sound Transmission Loss. Physically, STL can be interpreted as the ability of the material not to pass sound from sound source space to the receiving room next to it [3].

The value of TL on a material can be used as follows:

$$
\begin{aligned}
& T L=N R+10 \log \frac{s}{A_{\text {rac }}} \\
& N R=L 1-L 2
\end{aligned}
$$

With,

$\mathrm{NR}=$ Noise Reduction $(\mathrm{dB})$

$\mathrm{L} 1=$ Level of sound in the source room

$\mathrm{L} 2=$ Level of sound in the receiver room

$\mathrm{S}=$ area of the partition material sample $\left(\mathrm{m}^{2}\right)$

Arec $=$ total sound absorption in the receiving room ( $\mathrm{m}^{2}$ sabine)

Based on [5], the ability of a material to reduce noise from a material can be shown in a single value called a sound transmission class (STC).

In this paper, an acoustic panel made from bamboo that analyzed with thick and thin woven bamboo also a combination of both. The acoustic performance that analyzed is an absorption coefficient and sound transmission loss. Through this research, it is expected to be able to show the acoustic capabilities of bamboo woven panels in absorbing so that later it can be an alternative acoustic material as part of overcoming the problem of room acoustics.

In section II, explained about the process of measuring the acoustic performance of bamboo panels, in section iii the results of measurements were discussed and finally in section 4th explained the conclusions obtained from the research.

\section{Methodology}

As stated in part I, to obtain the acoustic performance of bamboo webbing, it is carried out through 2 types of measurements, namely the measurement of absorption coefficients and sound insulation measurements. Absorption measurements were carried out to determine the performance

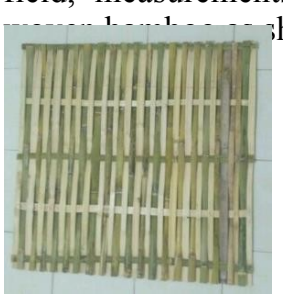

(a)

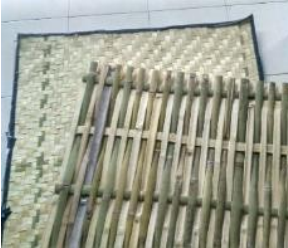

(d)

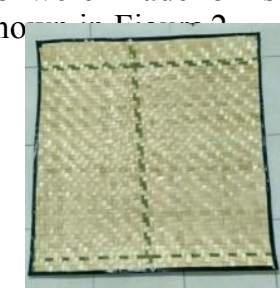

(b)

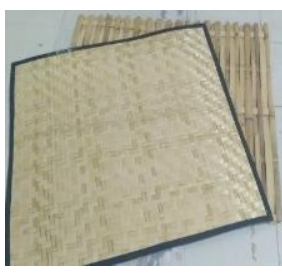

(c)

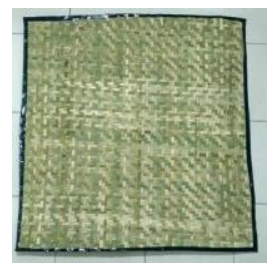

(e)
Fig. 2. Variation of the Material test

(a). thick woven bamboo; (b). thin woven bamboo; (c). combination of thick and thin (thin on top);

(d). combination of thin and thick (thick on top); (e). thin woven bamboo skin

\section{A. Absorption Coefficient}

The measurement of the absorption coefficient is based on ISO 354. Base on ISO 354, the size of the test material is at least $10 \mathrm{~m}^{2}$ and placed in the middle of the room. The Coefficient absorption measurement was carried out using the reverberation time method according to [2]. Figure 3 shows a scheme of the absorption coefficient measurement on this research.

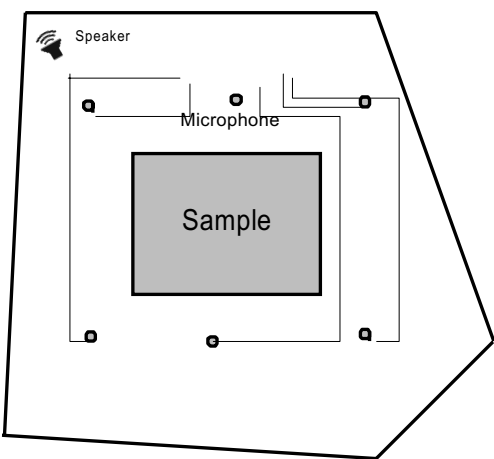

(a) 


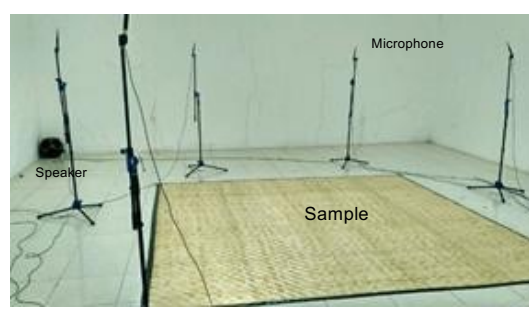

(b)

Fig. 3. Absorption coeficient measurement.

(a) schematic, (b) real measurement

To obtain the absorption coefficient value carried out based on the provisions of [2]. The volume of the reverberation chamber on measurement is $148 \mathrm{~m}^{3}$. Measurement use one speaker with two positions, and six microphones with a minimum distance between microphones of $1.5 \mathrm{~m}$ then distance microphone with a surface of at least $0.75 \mathrm{~m}$. The dimension of partition was tested is $3 \mathrm{~m} \times 3 \mathrm{~m}$.

\section{B. Sound Transmission Loss}

The Sound insulation power performance (STL) measurement carried out in the reverberation chamber and anechoic chamber according to the provisions of [4]. Measurement of the insulation materials following the scheme as at Figure 4 with a dimension of the material test (sample) is $1.08 \mathrm{~m} \mathrm{x} 1.12 \mathrm{~m}$.

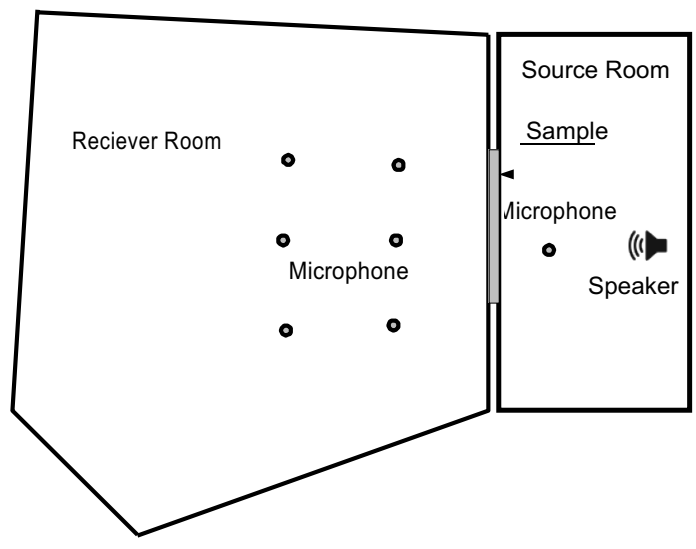

Fig. 4. schematic of STL measurement

Based on Figure 4, STL measurements are carried out by measuring difference SPL when sources in anechoic space then listeners in the reverberation room and vice versa. The TL value of the resulting material is the average value of the two TL values are measure [4]. From the TL value obtained, it is then used to determine the STC value following [5].

\section{RESULTS AND DISCUSSION}

\section{A. Results}

\section{1) Absorption coefficient $(\alpha)$}

As mention in part I, the acoustic performance of bamboo material is known through the sound absorption parameters $(\alpha)$ and sound insulation (TL). The absorption coefficient value is obtained by measuring the reverberation time value of room when empty and the material is placed. Table 1 shows the $\mathrm{T}_{60}$ values measured when the room empty and there are ingredients for 5 material variations

TABLE I. The value of $\mathrm{T}_{60}$ for absorption coefficients measurement

\begin{tabular}{|c|c|c|c|c|c|}
\hline Frequency $(\mathrm{Hz})$ & & Reve & eratiol & Time (s) & \\
\hline & $\begin{array}{r}\text { Empty } \\
(\mathrm{T} 1)\end{array}$ & $\begin{array}{c}\mathrm{A} \\
(\mathrm{T} 2)\end{array}$ & $\begin{array}{c}\mathrm{B} \\
(\mathrm{T} 2)\end{array}$ & $\begin{array}{c}\text { C } \\
(\mathrm{T} 2)\end{array}$ & $\begin{array}{c}\mathrm{D} \\
(\mathrm{T} 2)\end{array}$ \\
\hline All(F) & 6,82 & 6,64 & 6,59 & 6,94 & 6,19 \\
\hline 100 & 9,98 & 11,03 & 9,73 & 13,17 & 10,17 \\
\hline 125 & 6,47 & 6,49 & 6,40 & 6,96 & 5,89 \\
\hline 160 & 6,69 & 6,21 & 6,61 & 6,04 & 5,80 \\
\hline 200 & 5,78 & 5,77 & 5,58 & 5,48 & 5,38 \\
\hline 250 & 6,31 & 6,36 & 6,14 & 5,82 & 5,86 \\
\hline 315 & 7,15 & 6,90 & 6,92 & 6,31 & 6,44 \\
\hline 400 & 6,94 & 6,73 & 6,76 & 5,70 & 6,20 \\
\hline 500 & 7,65 & 7,15 & 7,13 & 5,90 & 6,49 \\
\hline 630 & 7,49 & 6,96 & 6,84 & 5,27 & 6,25 \\
\hline 800 & 7,07 & 6,57 & 6,31 & 4,44 & 5,79 \\
\hline 1000 & 6,75 & 6,15 & 5,88 & 3,90 & 5,10 \\
\hline 1250 & 6,16 & 5,48 & 5,15 & 3,30 & 4,26 \\
\hline 1600 & 5,51 & 4,56 & 4,31 & 2,94 & 3,40 \\
\hline 2000 & 4,73 & 3,69 & 3,30 & 2,88 & 2,64 \\
\hline 2500 & 4,25 & 3,47 & 2,86 & 2,84 & 2,43 \\
\hline 3150 & 3,92 & 3,30 & 2,66 & 2,80 & 2,33 \\
\hline 4000 & 3,44 & 2,94 & 2,31 & 2,64 & 2,22 \\
\hline 5000 & 3,02 & 2,62 & 2,15 & 2,89 & 2,13 \\
\hline
\end{tabular}

By using equation (3), the absorption coefficient value can be calculated and the results as shown in Figure 5.

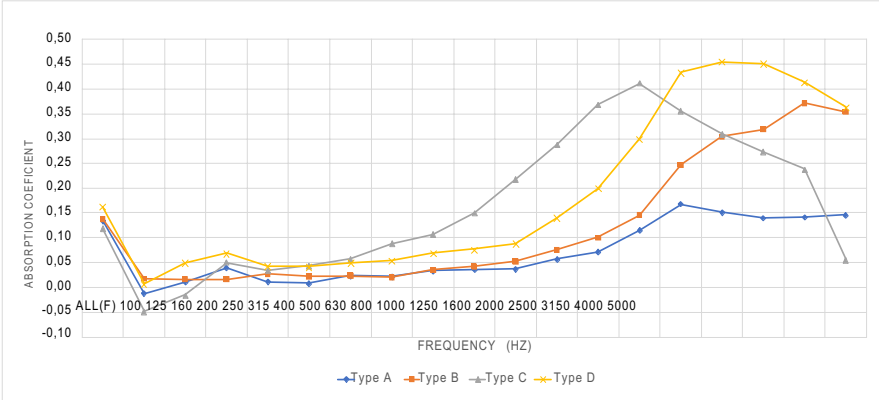

Fig. 5. Coefficient absorption number of woven bamboo.

Refer to figure 5, it can be seen that the absorption coefficient value at all frequencies is relatively small especially at low frequency. Based on Figure 5, it is also seen that generally, at intermediate frequencies, material $\mathrm{C}$ has the highest absorption coefficient than other materials $\left(\alpha_{A}<\alpha_{B}\right.$ $\left.<\alpha_{D}<\alpha_{C}\right)$. 


\section{2) Transmission loss (TL)}

The TL value is obtained by measuring the differences SPL between the source and receiver room. Also, corrections are needed to be made by measuring the effects of reflections in the listening room using the reverberation time of the receiver room. By using equations (4) and equation (6), the TL values for each ingredient are shown in the graph in Figure 6 below.

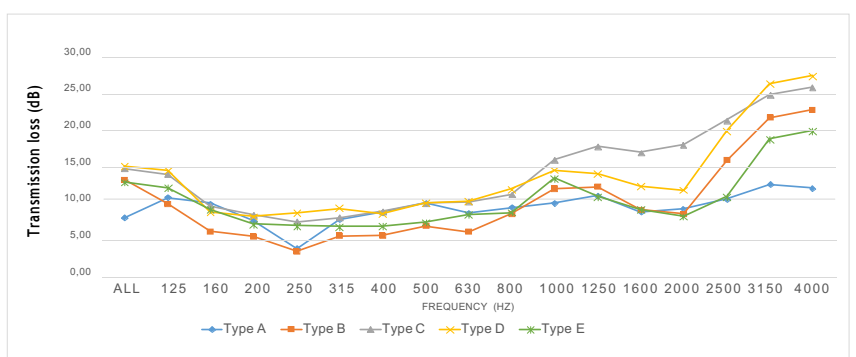

Fig. 6. The value of TL woven bamboo

Based on Figure 6, it can be seen that at low frequencies $(<250 \mathrm{~Hz})$, all woven bamboo materials have a TL value of around $2 \mathrm{~dB}$ up to $14 \mathrm{~dB}$. At the medium frequency (250$800 \mathrm{~Hz}$ ), material A, C, and D have a TL that higher than the other materials, for example, $9.36 \mathrm{~dB}$ at a frequency of $500 \mathrm{~Hz}$. while the material $\mathrm{B}$ and $\mathrm{E}$ which have TL values of $6.27 \mathrm{~dB}$ and $6.77 \mathrm{~dB}\left(\mathrm{TL}_{\mathrm{B}}<\mathrm{TL}_{\mathrm{E}}<\mathrm{TL}_{\mathrm{C}}<\mathrm{TL}_{\mathrm{D}}\right.$ and $\left.\mathrm{TL}_{\mathrm{A}}\right)$. At high frequencies $(>1000 \mathrm{~Hz})$, the TL value of the materials is increased. The maximum TL value of the material occurs at a frequency of $4000 \mathrm{~Hz}$ with the value of material $\mathrm{D}$ of $26.7 \mathrm{~dB}$, material C $25.16 \mathrm{~dB}$, material $\mathrm{B}$ of $22.1 \mathrm{~dB}$, material E of $19.2 \mathrm{~dB}$, and material $\mathrm{A}$ of $11.38 \mathrm{~dB}$.

According to [5], from the TL value, we can obtain the STC of each material. Table 2 shown the value of STC performance for five material were testing.

TABLE II. The STC value of materials test

\begin{tabular}{cc}
\hline Type of Material & STC (dB) \\
\hline A & 9 \\
B & 9 \\
C & 14 \\
D & 12 \\
E & 9 \\
\hline
\end{tabular}

From Table II, the STC value of the material is low. It means that is not good for isolating sound, but this material can be used as an additional panel on the wall in the room. In the table also shown that the material can isolate sound with the highest to lowest STC values respectively are material C, material $\mathrm{D}$, material $\mathrm{B}$, material $\mathrm{E}$, and material $\mathrm{A}$. This means that material $\mathrm{C}$ can isolate the sound better than the other material.

\section{B. Discussion}

The performance of acoustic materials in controlling sound includes the ability to absorb and isolate sound. As a sound-absorbing material, the acoustic material will control the reflections that hit it so that it does not cause excessive reverberation. The greater the value of the absorption coefficient, the greater the ability to absorb the energy that comes before being reflected in the same room. While the ability of sound insulation, the material will absorb and reduce energy about it before being forwarded to another room.

Based on the measurement, the sound absorption ability of bamboo material is relatively small below 0.5 . This is because the dimensions (thickness) of the material are relatively thin. Besides, ingredients are made (tested) without any additional ingredients. Similar conditions occur in relatively small sound insulation performance. However, the use of bamboo woven material as an alternative material for wood substitution is still possible to develop. Toimprove the ability of acoustic absorption performance can be made into a multilayer on the back or a combination of other materials such as adding a layer of lime on the outside. In this way, it is expected to increase the power of sound insulation, while visually it still looks beautiful.

\section{CONCLUSION}

Based on the results of measurements and data analysis it can be concluded that bamboo plaiting materials have good ability to absorb at frequencies above $1000 \mathrm{~Hz}$, but are not good at low frequencies. While in the performance of sound isolation, bamboo woven material has an STC value are $9 \mathrm{~dB}$ for type A, $9 \mathrm{~dB}$ for type $\mathrm{B}, 14 \mathrm{~dB}$ for type $\mathrm{C}, 12 \mathrm{~dB}$ for type $\mathrm{D}$, and $9 \mathrm{~dB}$ for type $\mathrm{E}$. To improve the acoustic performance of bamboo matting, a combination or additional coating that can be done on the woven surface. So that, woven bamboo materials can be used as one of the economical alternatives to wood substitutes.

\section{REFERENCES}

[1] Z. Maekawa, P. Lord. Environmental and Architectural Acoustics. London: Chapman and hall, 1994.

[2] ASTM C423-17. Standard Test Method for Sound Absorption and Sound Absorption Coefficients by the Reverbrationeration Room Method. 2017.

[3] J. T. Cox, Acoustic Absorbers and Diffusers. UK: University of Salford, 2004.

[4] ASTM E90. "Laboratory Measurement of Airborne Transmission Loss of Building Partition and elements". 2009.

[5] ASTM E413-04. Classification Rating Sound Insulation. 2004

[6] L. Karlinasari, at.al. Acoustical properties of particleboards made from betung bamboo as Building Construction Material. BioSources, 2012.

[7] E. A. Widjaja, Identity Kits for the Bamboo species in Java. Bogor: LIPI, 2001.

[8] A. F. Pinto, dkk. Aplikasi Rajutan Bambu Sebagai Tulangan Balok Beton. Malang, Universitas Brawijaya (Indonesian version), 2016.

[9] Y. H. Bakhtiar, S. Indrawati, and Suyatno. Evaluation of reverberation chamber relation to reverberation time and distribusion of sound pressure level with ISO 354 as standart in building physics laboratory of physics departement ITS, IOP Conf. Series: Journal of Physics: Conf. Series 1153 (2019) 012004, IOP Publishing doi:10.1088/1742-6596/1153/1/01200 